\title{
Análise Comportamental: uma abordagem aplicada ao ambiente organizacional para melhoria e redução da taxa de absenteísmo
}

\section{Behavioral Analysis: an approach applied to the organizational environment to improve and reduce absenteeism rate}

Thayane Cesar Marino

Instituição: Unidade de Ensino Superior do Sul e Sudeste do Maranhão (UNISULMA), Imperatriz-MA

Julia Camila da Cruz Freitas

Instituição: Unidade de Ensino Superior do Sul e Sudeste do Maranhão (UNISULMA), Imperatriz-MA

Rhayana Claudyelle Carneiro Duarte

Centro Universitário de João Pessoa - UNIPÊ, João Pessoa-PB

\section{RESUMO}

Este estudo tem como enfoque principal explorar a análise comportamental de Skinner identificando quais contingências de reforçamento aplicar para redução da taxa de absenteísmo no ambiente organizacional, bem estar e produtividade do colaborador.

Palavras-chave: Psicologia organizacional; Análise comportamental; Absenteísmo.

\section{ABSTRACT}

The main focus of this study is to explore Skinner's behavioral analysis by identifying which reinforcement contingencies to apply in order to reduce the absenteeism rate in the organizational environment, employee well-being and productivity.

Keywords: Organizational psychology; Behavioral analysis; Absenteeism.

\section{INTRODUÇÃO}

A Análise Comportamental é uma abordagem que tem tomado cada vez mais espaço na Psicologia, especialmente a corrente teórica de Skinner, que se fundamenta no pressuposto que os estímulos podem influenciar um determinado comportamento, gerando consequências e efeitos que influi na possibilidade dessa ação voltar a ocorrer. Dessa forma, o analista comportamental na organização, com a utilização de contingências de reforçamentos explora a comunicação entre um organismo e o ambiente em que ele está inserido, para propor mudanças que promovam melhoria e redução da taxa de absenteísmo.

Segundo Sender e Fleck (2017), o colaborador não gostar do que faz na organização e não estar bem onde está pode acarretar em um estado infeliz, como consequência, este indivíduo tenderia a ter menos energia, tomar decisões imprudentes, reduzir sua produtividade e sua contribuição para a organização. Este estudo poderia desencadear também um aumento do nível de absenteísmo e turnover, que são 
comportamentos negativos para a organização, e da quantidade de licenças devido o cansaço e exaustão e outras doenças, assim como, baixa produtividade, desempenho abaixo do desejado.

\section{OBJETIVO}

Analisar o modelo comportamental de Skinner, como corrente teórica da Psicologia, identificando quais contingências de reforçamento utilizar para promoção da redução da taxa de absenteísmo dos colaboradores dentro da organização.

\section{MÉTODO}

Este estudo trata-se de uma revisão bibliográfica, fundamentada por livros e artigos científicos tendo como foco principal a corrente teórica de Skinner, acreditando que seus pressupostos proporcionam uma melhor compreensão para alcance do objetivo proposto na pesquisa. Como critérios de seleção utilizou-se artigos em língua portuguesa, publicados entre 2017 e 2021 na plataforma de dados Psicologia (PePSIC), Scientific Electronic Library Online (SciELO), na Biblioteca Virtual em Saúde (BVS). Foram utilizados descritores como "análise comportamental", "contingências de reforçamento", "psicologia organizacional" e "absenteísmo" para realização do estudo.

\section{REVISÃO BIBLIOGRÁFICA}

A Psicologia Comportamental carrega grandes nomes que a fundamentam como Watson e Skinner. A base teórica de Skinner (2003) traz o conceito de Comportamento Operante no qual consiste em que as consequências do comportamento, eliciado por agentes externos, podem retroagir sobre o organismo e quando isto acontece, podem alterar a probabilidade de o comportamento ocorrer novamente. O autor afirma que quando se trata do comportamento humano existem tendências ou predisposições que podem influenciar o indivíduo a se comportar de determinada maneira, ou seja, Skinner afirma que se pode, não determinar um comportamento, mas tornar a ocorrência do mesmo mais provável.

Skinner (2003) propõe que se o gestor deseja os colaboradores trabalhando de acordo com as suas especificações e sem absenteísmo precisa certificar-se de que o comportamento deles esteja sendo reforçado adequadamente, não somente com salários, mas também com adequadas condições de trabalho. Alocando o conceito de Comportamento Operante à organização pode-se afirmar que quando o colaborador recebe um estímulo de seu gestor, esse estímulo aumenta a probabilidade de o comportamento voltar a ocorrer no futuro. Nesse sentido, se o gestor gostaria reduzir o número de absenteísmo da sua equipe, ao invés de utilizar ferramentas como medidas disciplinares, adicionar um estímulo positivo ou utilizar a punição negativa para obtenção do resultado desejado. 
Nessa perspectiva, os métodos que envolvem o uso do sistema de reforçamento positivo podem está relacionado à importância da motivação, reconhecimento, feedback, treinamento e desenvolvimento, benefícios, que além de auxiliar na redução do absenteísmo, produz um ambiente corporativo agradável e de forma eficaz gerência e maximiza o desempenho desejável do colaborador, logo, o trabalhador terá maior probabilidade de se sentir satisfeito.

\section{DISCUSSÃO}

No que se refere ao reforço positivo dentro da organização, Abade e Rocha (2019) afirmam que esse conceito consiste em fazer com que uma resposta ou comportamento seja reforçado pela inclusão de algo, como elogio ou uma recompensa direta, no contexto organizacional é válido uma premiação para todos aqueles que reduzirem a taxa de absenteísmo, uma folga a mais, homenagem ou ajustes na remuneração.

Assim como a punição negativa pode ser similarmente utilizada, como por exemplo, é posto que todos os colaboradores da empresa receberão um vale-compras em um mercado local, entretanto, os colaboradores que apresentarem uma taxa de absenteísmo acima do esperado não receberão tal benefício. No entanto, Skinner (2003) afirma que a punição pode não alcançar o resultado desejado, pois pode ocorrer um efeito imediato na redução de uma tendência a se comportar, mas isso pode ser equivocado, visto que, este novo padrão comportamental pode não ser permanente.

\section{CONSIDERAÇÕES FINAIS}

Durante o estudo foi possível aprofundar o conceito de análise comportamental e sua aplicação no âmbito corporativo, identificar as formas de intervenção e o uso do sistema de reforçamento positivo, que promovem o bem estar do colaborador e a produtividade, gerando a redução das taxas de absenteísmo. Esse estudo pretende contribuir na propagação de reflexões a fim de enriquecer a literatura a respeito do modelo de método adotado na pesquisa em questão, além de reafirmar a importância do analista comportamental nas organizações. 


\section{REFERÊNCIAS}

ABADE, Armindo Meira; ROCHA, Adriana Cristina. O comportamento operante na perspectiva da análise comportamental: uma revisão bibliográfica. Revista Uningá, Maringá, v. 56, n. 1, p. 10-21, jan. 2019.

SENDER, Gisela; FLECK, Denise. As organizações e a felicidade no trabalho: Uma perspectiva integrada. Revista de Administração Contemporânea, v. 21, n. 6, p. 764-787, 2017.

SKINNER, Burrhus Frederic. Ciência e comportamento humano. São Paulo: Martins Fontes, 2003. 